\title{
Patterns of injuries and predictors of inhospital mortality in trauma patients in Saudi Arabia
}

This article was published in the following Dove Press journal:

Open Access Emergency Medicine

\section{Mostafa A Abolfotouh' \\ Mohamed A Hussein ${ }^{2}$ \\ Sameh M Abolfotouh ${ }^{3}$ \\ Alanoud Al-Marzoug ${ }^{4}$ \\ Suliman Al-Teriqi ${ }^{5}$ \\ Abeer Al-Suwailem ${ }^{6}$ \\ Ra'ed A Hijazi ${ }^{7}$}

'Research Training and Development Section, King Abdullah International Medical Research Center, King Saud Bin Abdulaziz University for Health Sciences, Riyadh, Saudi Arabia; ${ }^{2}$ Biostatistics and Bioinformatics Department King Abdullah International Medical Research Center, King Saud Bin Abdulaziz University for Health Sciences, Riyadh, Saudi Arabia; ${ }^{3}$ OrthoCure Medical Center, Dubai, UAE; ${ }^{4}$ College of Medicine, King Saud Bin Abdulaziz University for Health Sciences, Riyadh, Saudi Arabia; ${ }^{5}$ College of Medicine, Imam Muhammad Ibn Saud Islamic University, Riyadh, Saudi Arabia; ${ }^{6}$ College of Medicine, King Saud University, Riyadh, Saudi Arabia; ${ }^{7}$ Emergency Care Center, King Abdulaziz Medical City, Ministry of National Guard-Health Affairs, Riyadh, Saudi Arabia
Correspondence: Mostafa A Abolfotouh King Abdullah International Medical Research Center (Mail Code 1515), King Saud Bin Abdulaziz University for Health Sciences (KSAU-HS), Ministry of National Guard-Health Affairs, POB 22490, Riyadh 1 I426, Saudi Arabia

Email mabolfotouh@gmail.com
Background: The aim of this study was to describe the pattern of traumatic injuries and determine the predictors of inhospital mortality in patients admitted to the emergency department.

Patients and methods: This is a retrospective cohort study of 3,786 patients with traumat injuries admitted to the emergency department of King Abdulaziz Medical City, Riyadh, Saudi Arabia, between January 2012 and December 2014. Data on patient characteristics, trauma characteristics and outcomes were extracted from medical records. A negative binomial regression model was utilized to identify significant predictors of inhospital mortality.

Results: Of all injured patients, $77.5 \%$ were male, $29.8 \%$ were aged $15-25$ years and $25.7 \%$ were aged 26-45 years. Blunt trauma was the main mechanism of injury, including motor vehicle crashes (MVCs) in $52.0 \%$ and falls in $25.8 \%$ of patients. Most patients had injuries to the extremities $(61.3 \%)$, followed by the head $(32.2 \%)$, chest $(16.9 \%)$ and abdomen $(8.9 \%)$. Injuries were mild in $49.7 \%$ of patients, moderate in $30.2 \%$ and severe in $20.1 \%$. The sex of the patients was significantly associated with the mechanism of injury $(p<0.001)$, severity $(p<0.001)$, anatomical site of injury $(p<0.001)$, admission to the intensive care unit $(p<0.001)$, need for trauma team activation $(p<0.001)$ and type of transportation to hospital $(p<0.001)$. The predictors of inhospital mortality were age (rate ratio [RR] for each 10-year increase $=1.174$; $p<0.001)$, falls and burns $(\mathrm{RR}=2.337$ and $1.728 ; p<0.001)$ and moderate and severe injuries ( $\mathrm{RR}=6.438$ and $181.780 ; p<0.001)$.

Conclusion: Our results suggest different patterns of trauma injuries according to patient age and sex. MVCs were the leading cause of injuries, but falls and burns had the highest inhospital mortality. This suggests the need for a comprehensive national education and prevention programs that address all causes of injuries.

Keywords: MVCs, case fatality, injury severity, mechanism of injury, Saudi, causes of injury

\section{Introduction}

Injuries result in 16,000 deaths per day and more than 5 million deaths per year. ${ }^{1,2}$ They are one of the major causes of death worldwide and result in temporary or permanent disability with consequential social and economic impact. The leading causes of injury-related deaths include road traffic injuries (RTIs), interpersonal and self-inflicted violence, drowning, burns, poisoning and falls. ${ }^{2}$

Over the past decade, there has been a decline in traumatic injuries; however, the patterns vary widely by cause, age, sex and region. ${ }^{3}$ This decline is due to major efforts in tailored preventive programs that have been developed to address major underlying causes of injuries. For instance, US has made tremendous progress in reducing falls and traffic-related injuries and fatality in recent decades. ${ }^{4}$ This was possible 
via successful implementation and execution of preventive strategies and programs such as Stopping Elderly Accidents, Deaths and Injuries (STEADI) deployed by the US Center for Disease Control. ${ }^{5}$

In Saudi Arabia, RTIs account for more than $80 \%$ of all trauma admissions. ${ }^{6}$ In 2010, RTIs ranked second in the main causes of daily adjusted life years in Kingdom of Saudi Arabia (KSA), after major depressive disorder, and the third leading cause of death, accounting for $11.75 \%$ of total mortality. ${ }^{7}$ The Ministry of Health, in collaboration with the Ministry of Interior, launched a road safety program called Saher in $2009,{ }^{8}$ which is an automated system developed to manage traffic via electronic systems in major cities in Saudi Arabia. This system uses a digital camera network connected to the National Information Center to track any violations and to control traffic. Alghnam et $\mathrm{al}^{9}$ reported significant reductions in the severity and mortality of motor vehicle crash (MVC)-related injury following the implementation of this system. Saudi Arabia has also enforced seat belt law from December 5, 2000, making its use compulsory for all drivers and front seat passengers. ${ }^{10,11}$ Despite this remarkable progress on combating RTI, unfortunately there have been very few programs addressing other causes of injuries such as falls, burns and intentional injuries.

The burden of injuries in terms of morbidity, disability and mortality is augmented by injuries other than RTIs. This is especially important given the fact that the life expectancy of Saudi population is in a dramatic increase during the past few decades. This change in population structure is likely to lead to changes in patterns of trauma injuries and mortality. ${ }^{12,13}$ To properly plan for comprehensive education and prevention programs to combat trauma of causes other than MVCs, studies are needed to understand their patterns. Thus, the aim of this study was to describe the pattern of traumatic injuries and predictors of in-hospital mortality in patients admitted to the emergency department of King Abdulaziz Medical City (KAMC), Riyadh, Saudi Arabia, between January 2012 and December 2014.

\section{Patients and methods}

The study was carried out at the Emergency Care Center (ECC) of KAMC, a 900-bed tertiary-care Joint Commission International-accredited academic center. The ECC of KAMC is the largest in Riyadh and has 132 beds. The ECC provides free, high-quality emergency care for National Guard employees, their families and anyone who is critically ill or injured and seeks care. The ECC receives approximately 32,000 visits per year and also serves as a referral trauma center for patients across the entire KSA. This study was approved by the institutional review board (IRB) of the Ministry of National Guard-Health Affairs (MNG-HA) in Riyadh, Saudi Arabia (ref no. RSS15/003).

\section{Study design}

This is a retrospective cohort study of 3,786 patients with trauma injuries who were admitted to the ECC between January 2012 and December 2014.

\section{Data collection}

Data were extracted from electronic medical records and patient charts. Patient characteristics included age and sex. Trauma characteristics included the type and mechanism of injury, Injury Severity Score (ISS), adult trauma score and trauma team activation. Outcomes included inhospital mortality, hospital disposition, emergency room (ER) disposition and length of stay (LOS).

Injuries were assessed and classified according to the ISS, ${ }^{14-16}$ Glasgow Coma Scale (GCS) ${ }^{17,18}$ and Revised Trauma Score (RTS). ${ }^{19}$ The injury type was classified as blunt, burn/ scald or penetrating (gunshot/stab wound or others). The injury mechanism was classified into one of the five groups: motor-vehicle-related injuries (including MVCs and injuries to pedestrians and motorcycle riders), burns (either from fire, flame or liquid), falls, intentional injuries (comprising selfinflicted and suicidal injuries, and injuries purposely inflicted by others, such as homicidal injuries) and other injuries. This last group included drowning/submersion, suffocation and foreign body-mediated injuries. In our hospital, trauma activation is based on a complex algorithm that involves the sequential assessment of several criteria of physiological, anatomical, mechanism of injury and logistical domains.

The ER LOS was defined as the time spent from the patient's arrival at the ER until disposition to the intensive care unit (ICU), burn unit, morgue, operating room or ward. The hospital LOS was the time from ER disposition until discharge. The ICU LOS was the time spent in the ICU following disposition from the ER. All data were collected after obtaining the approval of the IRB of the MNG-HA (ref no. RSS15/003). Consent was deemed not applicable by IRB due to the fact that all data utilized in this study were extracted retrospectively from the hospital health information system.

\section{Statistical analyses}

All categorical variables were summarized and reported in terms of frequency and proportion, and continuous variables were summarized and reported in terms of mean and SD. 
Categorical variables were compared using Chi-square and Fisher's exact tests, as appropriate. Continuous variables, including ISS, GCS score, RTS and LOS, were compared using Student's $t$-tests. To determine the predictors of inhospital mortality, we analyzed mortality by generalized linear models with log link function and negative binomial distribution. Mortality was included as the dependent variable, and age in years, ISS, sex and mechanism of injury were included as independent variables. The results were reported in terms of rate ratio (RR) and the corresponding 95\% CI. Statistical significance was determined at a type I error rate of 0.05 . All analyses were performed with SPSS version 21 (IBM Corporation, Armonk, NY, USA).

\section{Results}

The study population consisted of 3,786 patients presenting with injuries during a period of 3 years, $77.5 \%$ of whom were male. A little less than one third (29.8\%) of patients were aged $15-25$ years and $25.7 \%$ were aged $26-45$ years. The mean age of female patients (33.7 years) was significantly higher than that of male patients (28.4 years, $\mathrm{t}=5.39, p<0.001$; Table 1 ).

The majority of traumatic injuries were from blunt trauma in the form of MVCs (52.0\%) and falls (25.8\%). Injuries from MVCs made up a higher proportion of all injuries in males $(57.1 \%)$ than in females (34.4\%), whereas injuries from falls among females (42.7\%) were double that of males $(20.9 \%)$. Burn/scald injuries have only accounted for $6.8 \%$ of all injuries, equally distributed between burns due to fire flames $(\mathrm{n}=134,51.9 \%)$ and burns due to liquid $(\mathrm{n}=124,48.1 \%)$. Intentional injuries accounted for $5.1 \%$ of all injuries in the form of homicide injuries and injuries purposely inflicted by others $(4.8 \%)$ and suicide and self-inflicted injuries $(0.3 \%$; Table 1$)$.

The injuries were affecting a total of 4,519 anatomical sites, as they could affect more than one site in each patient. Injuries to the extremities affected $61.3 \%$ of patients, followed by injuries to the head $(32.2 \%)$, chest $(16.9 \%)$ and abdomen (8.9\%). The proportions of males affected by head, chest and abdomen injuries were significantly higher than those of females ( $p<0.001$ each; Table 1$)$.

The distribution of different types of traumatic injury according to sex and age of the patients is shown in Figure 1. Injuries resulting from MVCs were the main type overall in males, whereas fall-related injuries were most common among females. In the 0-4-year age group, injuries were distributed fairly evenly between four types (MVCs, falls, burns and others). Injuries resulting from MVCs made up progressively higher proportions of the total as age increased, up to maximum rates in the 15-25-year age group (70.3\% in men and $59.8 \%$ in women); the rates then fell as age increased further. The proportions of injuries resulting from falls decreased as age increased up to the 15-25-year age group, then increased through all higher age groups, reaching maximum rates in individuals aged $\geq 65$ years $(53.3 \%$ in men and $87.0 \%$ in women). Injuries from burns and scalding formed a much higher proportion of all injuries in the $0-4$ year age group than in other groups (Table 1).

As summarized in Table 1, 49.7\% of all injuries were mild in severity, $30.2 \%$ were moderate and $20.1 \%$ were severe. The proportions were significantly different in males and females with higher rates of severe injuries in males and higher rates of mild injuries in females $(p<0.001)$. Among all injured patients, $56.3 \%$ were disposed from ER to the wards. The patterns of disposition were significantly different in males and females $(p<0.001)$. The sex of the patients was also significantly associated with the requirement for trauma team activation, the need for ICU admission and the mode of transportation to the ER (all $p<0.001$ ).

The pattern of severity was different across the mechanism of injury by sex, where severity was significantly higher in males than in females, in injuries caused by MVCs $(p=0.009)$ and in intentional injuries $(p=0.004)$, as shown in Figure 2.

As summarized in Table 2, 178 patients (4.8\%) died in hospital, with $32.0 \%$ of those deaths occurring in patients aged $26-45$ years, $89.3 \%$ in patients with severe injuries, $69.7 \%$ in patients with head, neck and face injuries, $97.0 \%$ in patients who required ICU admission, $69.1 \%$ in patients transported by ambulance and $65.2 \%$ in patients who required trauma team activation. Inhospital mortality (as a percentage of patients in each age group) increased significantly with age (Chi-square for linear trend $=17.51, p<0.004$ ). The difference in mortality rate between males and females was only significant in the $26-45$-year age group ( $p=0.029)$. The highest rates of mortality were among patients with head, neck or face injuries (10.2\%), burn injuries (9.7\%) or severe injuries $(20.9 \%)$ and those who needed trauma team activation $(13.9 \%)$, transportation by Medevac (13.5\%) or ICU admission (12.6\%).

In a multivariable regression model, age, severity of injury and mechanism of injury were the significant predictors of inhospital mortality (Table 3 ). In this model, for every decade increase in age, there was a $17 \%$ increase in the risk of inhospital death $(\mathrm{RR}=1.174 ;$ 95\% CI 1.139-1.209; $p<0.001)$. Moderate and severe injuries had higher fatality rates than injuries of mild severity $(\mathrm{R} R=6.438$ and 181.780 , $p<0.001$, respectively). Controlling for age, sex and severity 
Table I Patterns of trauma injuries in 3,786 patients admitted to KAMC, Riyadh, Saudi Arabia

\begin{tabular}{|c|c|c|c|c|c|c|c|}
\hline \multirow[t]{2}{*}{ Characteristics } & \multicolumn{2}{|c|}{ All $(N=3,786,100 \%)$} & \multicolumn{2}{|c|}{ Male $(\mathrm{N}=2,934,77.5 \%)$} & \multicolumn{2}{|c|}{ Female $(\mathrm{N}=852,22.5 \%)$} & \multirow{2}{*}{$\begin{array}{l}\text { Sex difference } \\
\left(\chi^{2}, p \text {-value }\right)\end{array}$} \\
\hline & $\mathrm{n}$ & $\%$ & $n$ & $\%$ & $\mathrm{n}$ & $\%$ & \\
\hline \multicolumn{8}{|l|}{ Patients' characteristics } \\
\hline Age (years) & & & & & & & $42.16,<0.0001^{a}$ \\
\hline $0-5$ & 447 & 11.8 & 269 & 9.2 & 178 & 11.8 & \\
\hline $6-14$ & 449 & 11.9 & 338 & 11.5 & 111 & 13.0 & \\
\hline $15-25$ & 1,130 & 29.8 & 1,027 & 35.0 & 102 & 12.0 & \\
\hline $26-45$ & 974 & 25.7 & 803 & 27.4 & 171 & 20.1 & \\
\hline $46-64$ & 386 & 10.2 & 257 & 8.8 & 129 & 15.1 & \\
\hline $65+$ & 401 & 10.6 & 240 & 8.2 & 161 & 18.9 & \\
\hline Mean $( \pm S D)$ & \multicolumn{2}{|c|}{$29.62 \pm 21.62$} & \multicolumn{2}{|l|}{$28.4 \pm 19.7$} & \multicolumn{2}{|l|}{$33.7 \pm 26.8$} & $\mathrm{t}=5.39,<0.00 \mathrm{I}^{\mathrm{a}}$ \\
\hline \multicolumn{8}{|l|}{ Trauma characteristics } \\
\hline Mechanism of injury & & & & & & & $256.2 \mathrm{I},<0.00 \mathrm{I}^{\mathrm{a}}$ \\
\hline Burn/scald & 258 & 6.8 & 160 & 5.5 & 98 & 11.5 & \\
\hline MVCs & 1,969 & 52.0 & 1,676 & 57.1 & 293 & 34.4 & \\
\hline Falls & 977 & 25.8 & 613 & 20.9 & 364 & 42.7 & \\
\hline Intentional & 193 & 5.1 & 183 & 6.2 & 10 & 1.2 & \\
\hline Others & 389 & 10.3 & 302 & 10.3 & 87 & 10.2 & \\
\hline Team activation & & & & & & & $91.82,<0.001^{a}$ \\
\hline Not activated & 2,950 & 77.9 & 2,184 & 74.4 & 766 & 89.9 & \\
\hline Activated & 836 & 22.1 & 750 & 25.6 & 86 & 10.1 & \\
\hline Transportation & & & & & & & $11 \mathrm{I} .05,<0.00 \mathrm{I}^{\mathrm{a}}$ \\
\hline Ambulance & 1,518 & 40.2 & $|, 29|$ & 44.2 & 227 & 26.7 & \\
\hline Medevac & 223 & 5.9 & 192 & 6.6 & 31 & 3.6 & \\
\hline Private/police & 2,031 & 53.9 & 1,438 & 49.2 & 593 & 69.7 & \\
\hline \multicolumn{8}{|l|}{ Anatomical site ${ }^{\mathrm{b}}$} \\
\hline Head & 1,218 & 32.2 & 1,044 & 35.6 & 174 & 20.4 & $69.85,<0.00 I^{a}$ \\
\hline Chest & 641 & 16.9 & 550 & 18.7 & 91 & 10.7 & $30.54,<0.00 I^{a}$ \\
\hline Abdomen & 338 & 8.9 & 293 & 10.0 & 45 & 5.3 & $17.97,<0.00 \mathrm{I}^{\mathrm{a}}$ \\
\hline Extremities & 2,322 & 61.3 & $\mathrm{I}, 777$ & 60.6 & 545 & 64.0 & $3.22,0.073$ \\
\hline Disposition from ER & & & & & & & $51.18,<0.001^{a}$ \\
\hline Burn unit & 192 & 5.1 & 123 & 4.2 & 69 & 8.1 & \\
\hline ICU & 490 & 12.9 & 405 & 13.8 & 85 & 10.0 & \\
\hline Operating room & 908 & 24.0 & 752 & 25.6 & 156 & 18.3 & \\
\hline Ward & 2,132 & 56.3 & 1,598 & 54.5 & 534 & 62.7 & \\
\hline Morgue & $64^{c}$ & 1.7 & 56 & 1.9 & 8 & 0.9 & \\
\hline Need for ICU admission & & & & & & & $|4.35,<0.00|^{a}$ \\
\hline Yes & 1,089 & 26.7 & 888 & 30.3 & 201 & 23.6 & \\
\hline No & 2,697 & 73.3 & 2,046 & 69.7 & 651 & 76.4 & \\
\hline \multicolumn{8}{|l|}{ Trauma severity (ISS) } \\
\hline Mild (<9 points) & $\mathrm{I}, 882$ & 49.7 & 1,396 & 47.6 & 486 & 57.0 & $42.65,<0.00 I^{a}$ \\
\hline Moderate (9-15 points) & $\mathrm{I}, 143$ & 30.2 & 884 & 30.2 & 259 & 30.4 & \\
\hline Severe (>15 points) & 759 & 20.1 & 652 & 22.2 & 107 & 12.6 & \\
\hline ISS score (mean \pm SD) & \multicolumn{2}{|c|}{$10.2 \pm 11.2$} & \multicolumn{2}{|l|}{$10.8 \pm 11.8$} & \multicolumn{2}{|l|}{$8.1 \pm 8.7$} & $\mathrm{t}=7.40,<0.00 \mathrm{I}^{\mathrm{a}}$ \\
\hline GCS $($ mean \pm SD) & \multicolumn{2}{|c|}{$13.4 \pm 3.6$} & \multicolumn{2}{|l|}{$13.1 \pm 3.7$} & \multicolumn{2}{|l|}{$14.2 \pm 2.6$} & $\mathrm{t}=9.43,<0.00 \mathrm{I}^{\mathrm{a}}$ \\
\hline RTS $($ mean $\pm S D)$ & \multicolumn{2}{|c|}{$11.4 \pm 1.2$} & \multicolumn{2}{|l|}{$\mathrm{II} .4 \pm \mathrm{I} .3$} & \multicolumn{2}{|l|}{$11.6 \pm 0.9$} & $\mathrm{t}=6.52,<0.00 \mathrm{I}^{\mathrm{a}}$ \\
\hline LOS in ER $(h)$ & $14.7 \pm$ & & $15.1 \pm 20.6$ & & $13.4 \pm 17.6$ & & $\mathrm{t}=2.36,0.019^{\mathrm{a}}$ \\
\hline LOS in ICU (days) & $4.7 \pm 1$ & & $4.9 \pm 15.1$ & & $4.1 \pm 12.1$ & & $\mathrm{t}=1.5 \mathrm{I}, 0.13$ \\
\hline LOS in hospital (days) & $19.8 \pm$ & & $20.5 \pm 46.6$ & & $17.6 \pm 34.3$ & & $\mathrm{t}=1.96,0.05$ \\
\hline
\end{tabular}

Notes: a'Statistical significance. ${ }^{\text {b}}$ Categories are not mutually exclusive. 'This figure includes 40 dead on arrival.

Abbreviations: ER, emergency room; GCS, Glasgow Comma Scale; ICU, intensive care unit; ISS, Injury Severity Score; KAMC, King Abdulaziz Medical City; LOS, length of stay; MVCs, motor vehicle crashes; RTS, Revised Trauma Score.

of injury, victims of falls and burns/scalds had significantly higher fatality rate compared to those of MVCs $(\mathrm{RR}=2.337$ and $1.728, p<0.001$, respectively).

\section{Discussion}

In the current study, of 3,786 injured patients admitted to ER during the period of 3 years, the majority were injured 


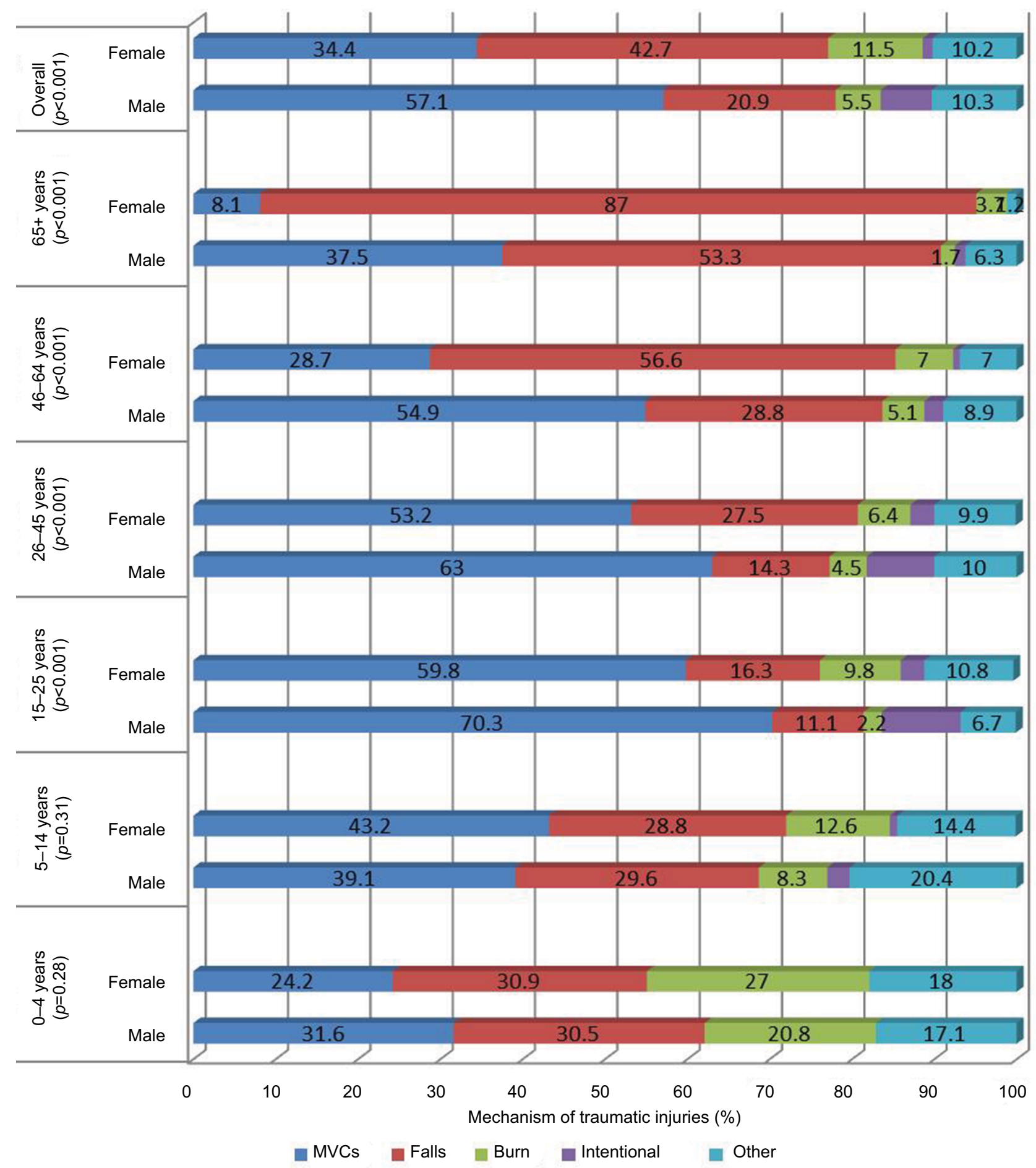

Figure I Distribution of mechanisms of traumatic injuries by sex and age groups.

Abbreviation: MVCs, motor vehicle crashes.

by MVCs, accounting for more than one-half of all injuries, followed by falls, accounting for one-fourth of all injuries. Other injuries were due to burn/scald as well as intentional injuries. Inhospital mortality rate in the current study was $4.8 \%$, a figure that is lower than that of the National Center for Technology Planning (NCTP) population $(9.5 \%)^{20}$ and that reported by Abbasi et $\mathrm{al}^{21}$ (8.8\%), comparable to a figure of $4.2 \%$ reported by Tyson et $\mathrm{al}^{22}$ and higher than a figure of $2.5 \%$ reported by Sieling et al. ${ }^{23}$ With regard to the location of death, the majority of deaths occurred in operating room 


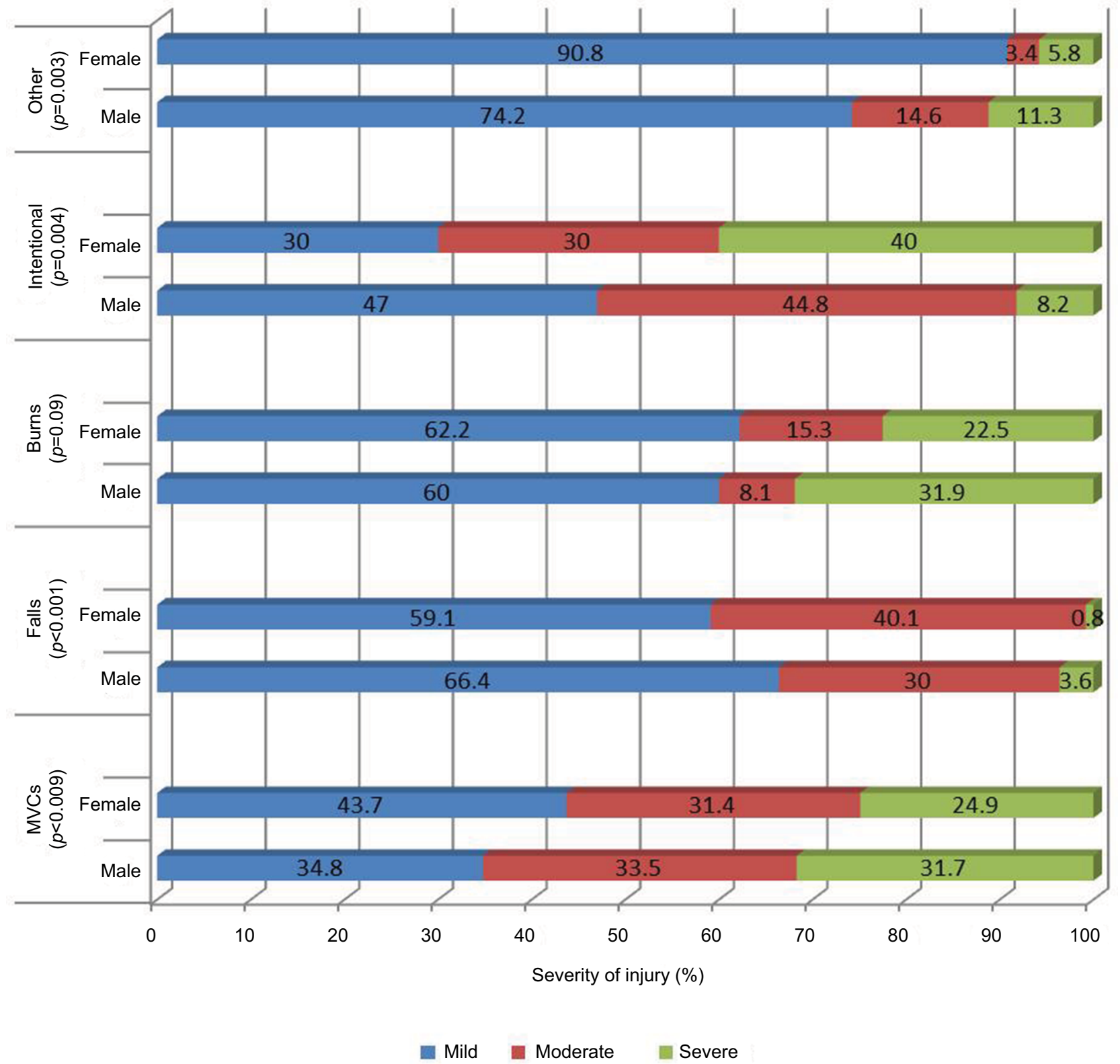

Figure 2 Association between the severity of injury and mechanisms of traumatic injuries by sex. Abbreviation: MVCs, motor vehicle crashes.

(OR), followed by ICU, then wards and burn unit. These figures are similar to figures of trauma deaths in a Brazilian university hospital. ${ }^{24}$

Inhospital mortality from trauma is influenced by the cause of injury, age and injury body areas. ${ }^{25-28}$ In our study, the predictors of inhospital deaths in trauma patients were as follows: age, mechanism of injury and severity. Injuries were more prevalent among young subjects aged $15-45$ years, yet the incidence of mortality was the highest in geriatric subjects, where it reached threefold. In our study, controlling for sex, severity and mechanism of injury, age was independently associated with increased fatality, where every 10 years of age resulted in $17 \%$ increase in fatality rate. This could be attributed to the presence of comorbidities and post-injury complications,$^{29}$ which were not measured in our study. However, it has been reported that the presence of multiple comorbidities is not necessarily an indicator of poor outcome. ${ }^{30,31}$

MVCs were the leading cause of injuries, in our study, being responsible for $52 \%$ of all injuries. This figure is five times higher than the global figure of $12 \%$ reported by Haagsma et al. ${ }^{3}$ Underlying reasons leading to such high figures are not clear, but several studies have implicated 
Table 2 Inhospital mortality rates in trauma patients admitted to KAMC, Riyadh, Saudi Arabia

\begin{tabular}{|c|c|c|c|c|c|}
\hline \multirow[t]{2}{*}{ Characteristics } & \multirow[t]{2}{*}{ Dead, n (\%) } & \multicolumn{4}{|c|}{ Case fatality rate (per 100 injured) } \\
\hline & & Male & Female & Overall & $p$-value \\
\hline Total & $178(100)^{\mathrm{a}}$ & 5.1 & 3.7 & 4.8 & 0.09 \\
\hline \multicolumn{6}{|l|}{ Age (years) } \\
\hline $0-5$ & II (6.2) & 2.3 & 2.5 & 2.5 & $0.76^{\mathrm{b}}$ \\
\hline $6-14$ & $14(7.9)$ & 3.0 & 3.2 & 3.1 & $0.76^{\mathrm{b}}$ \\
\hline $15-25$ & $47(26.4)$ & 4.1 & 4.2 & 4.2 & $0.6 \mathrm{I}^{\mathrm{b}}$ \\
\hline $26-45$ & $57(32.0)$ & 6.7 & 5.9 & 5.9 & 0.029 \\
\hline $46-64$ & $19(10.7)$ & 5.9 & 4.9 & 4.9 & 0.24 \\
\hline $65+$ & $30(16.8)$ & 8.8 & 7.5 & 7.5 & 0.24 \\
\hline$\chi^{2}, p$-value & & $|7.86,<0.00|$ & $3.43,0.63$ & $17.5 \mid, 0.004$ & \\
\hline \multicolumn{6}{|l|}{ Mechanism of injury } \\
\hline MVCs & $119(66.9)$ & 6.4 & 4.5 & 6.1 & 0.20 \\
\hline Burn/scald & $25(14.0)$ & 10.7 & 8.2 & 9.7 & 0.44 \\
\hline Falls & $24(13.5)$ & 2.6 & 2.2 & 2.5 & 0.69 \\
\hline Intentional & $5(2.8)$ & 1.6 & 22.2 & 2.6 & $0.018^{b}$ \\
\hline Other & $5(2.8)$ & 1.7 & 0.0 & 1.3 & $0.59^{\mathrm{b}}$ \\
\hline$\chi^{2}, p$-value & & $35.84,<0.001$ & $20.41,<0.001$ & $45.41,<0.001$ & \\
\hline \multicolumn{6}{|l|}{ Anatomical site ${ }^{c}$} \\
\hline Head/neck/face & $124(69.7)$ & 10.5 & 8.0 & 10.2 & 0.31 \\
\hline Chest & $59(33.1)$ & 9.3 & 8.8 & 9.2 & 0.88 \\
\hline Abdomen & $28(15.7)$ & 8.5 & 6.7 & 8.3 & 0.67 \\
\hline Extremities & $86(48.3)$ & 4.1 & 2.4 & 3.7 & 0.06 \\
\hline \multicolumn{6}{|l|}{ Team activation } \\
\hline Not activated & $62(34.8)$ & 1.9 & 2.6 & 2.1 & 0.27 \\
\hline Activated & $116(65.2)$ & 14.1 & 12.8 & 14.0 & 0.74 \\
\hline$\chi^{2}, p$-value & & $169.60,<0.001$ & $22.63,<0.001$ & $200.03,<0.001$ & \\
\hline \multicolumn{6}{|l|}{ Transportation } \\
\hline Ambulance & $123(69.1)$ & 8.0 & 9.5 & 8.2 & 0.48 \\
\hline Medevac & $30(16.8)$ & 15.1 & 6.5 & 13.9 & 0.20 \\
\hline Private/police & $25(14.1)$ & 1.2 & 1.3 & 1.2 & 0.76 \\
\hline$\chi^{2}, p$-value & & $106.64,<0.001$ & $30.81,<0.001$ & $135.09,<0.001$ & \\
\hline \multicolumn{6}{|l|}{ Disposition from ER } \\
\hline Burn unit & $16(9.0)$ & 8.1 & 8.7 & 8.3 & 0.89 \\
\hline ICU & $46(25.8)$ & 9.6 & 8.2 & 9.4 & 0.69 \\
\hline Operating room & $74(4 \mid .6)$ & 8.9 & 4.5 & 8.1 & 0.07 \\
\hline Ward & $18(10.1)$ & 0.6 & 1.5 & 0.8 & $0.10^{\mathrm{b}}$ \\
\hline$\chi^{2}, p$-value & & $501.63,<0.001$ & $96.36,<0.001$ & $604.88,<0.001$ & \\
\hline \multicolumn{6}{|l|}{ Need for ICU admission } \\
\hline Yes & I 37 (97.0) & 13.0 & 10.9 & 12.6 & 0.72 \\
\hline No & $4 I(3.0)$ & 1.6 & 1.4 & 1.5 & 0.44 \\
\hline$\chi^{2}, p$-value & & $165.12,<0.001$ & $39.67,<0.001$ & $207.91,<0.001$ & \\
\hline \multicolumn{6}{|l|}{ Trauma severity (ISS) } \\
\hline Mild (<9 points) & $3(1.7)$ & 0.1 & 0.2 & 0.2 & $1.0^{\mathrm{b}}$ \\
\hline Moderate (9-15 points) & $16(9.0)$ & 1.0 & 2.7 & 1.4 & $0.07^{\mathrm{b}}$ \\
\hline Severe (>15 points) & $159(89.3)$ & 22.0 & 22.5 & 22.1 & 0.91 \\
\hline$\chi^{2}, p$-value & & $469.46,<0.001$ & $120.33,<0.00 \mid$ & $594.66,<0.001$ & \\
\hline \multicolumn{6}{|l|}{ GCS } \\
\hline$<8$ "in coma" & $115(64.6)$ & 25.6 & 28.9 & 25.9 & 0.63 \\
\hline 9+ "out of coma" & $63(35.4)$ & 1.8 & 2.2 & 1.9 & 0.42 \\
\hline$\chi^{2}, p$-value & & $403.67,<0.001$ & $85.79,<0.001$ & $497.80,<0.001$ & \\
\hline \multicolumn{6}{|l|}{ RTS } \\
\hline$<3$ "no care" & $0(0.0)$ & 0.0 & 0.0 & 0.0 & - \\
\hline 3-10 "immediate care" & $119(68.0)$ & 22.4 & 20.0 & 22.1 & 0.66 \\
\hline II "urgent" & $19(10.9)$ & 4.4 & 2.4 & 3.9 & 0.33 \\
\hline 12 "can be delayed" & $37(21.1)$ & 1.1 & 2.1 & 1.4 & 0.08 \\
\hline$\chi^{2}, p$-value & & $367.17,<0.001$ & $55.76,<0.001$ & $434.95,<0.001$ & \\
\hline
\end{tabular}

Notes: a This figure does not include dead on arrival. ' ${ }^{6}$ Fisher's exact test was applied. 'Categories are not mutually exclusive.

Abbreviations: ER, emergency room; GCS, Glasgow Comma Scale; ICU, intensive care unit; ISS, Injury Severity Score; KAMC, King Abdulaziz Medical City; MVCs, motor vehicle crashes; RTS, Revised Trauma Score. 
Table 3 Predictors of inhospital mortality among trauma-injured patients

\begin{tabular}{lllll}
\hline Factor & $\begin{array}{l}\text { Case } \\
\text { fatality (RR) }\end{array}$ & $\begin{array}{l}\mathbf{9 5 \%} \\
\text { LCL }\end{array}$ & $\begin{array}{l}\text { 95\% } \\
\text { UCL }\end{array}$ & p-value \\
\hline Female vs. male & 1.096 & 0.930 & 1.292 & 0.274 \\
Age in I0 years & 1.174 & 1.139 & 1.209 & $<0.001$ \\
Injury severity & & & & \\
$\quad$ Moderate vs. mild & 6.438 & 4.037 & 10.267 & $<0.001$ \\
$\quad$ Severe vs. mild & 181.780 & 116.880 & 282.716 & $<0.001$ \\
Mechanism of injury & & & & \\
Falls vs. MVCs & 2.337 & 1.865 & 2.929 & $<0.001$ \\
$\quad$ Burn/scald vs. MVCs & 1.728 & 1.433 & 2.085 & $<0.001$ \\
Intentional vs. MVCs & 1.221 & 0.847 & 1.759 & 0.285 \\
$\quad$ Others vs. MVCs & 0.282 & 0.575 & 1.175 & 0.511 \\
\hline
\end{tabular}

Abbreviations: LCL, lower confidence limit; MVCs, motor vehicle crashes; RR, rate ratio; UCL, upper confidence limit.

high speed, driver errors and lack of basic skills for safe driving and lack of law enforcement. ${ }^{32-34}$ These injuries were significantly higher among males than females, possibly due to their greater exposure of driving and other risk-taking behaviors. ${ }^{35,36}$ Injuries due to MVCs in our study accounted for two-thirds of inhospital deaths, which is more than double the global figure of $31 \%,{ }^{3}$ but consistent with those of other studies in the region. ${ }^{37-40}$ The case fatality from MVCs is twofold to threefold higher in males than in females in developing countries. ${ }^{41}$ Yet, in our study, there was no sex difference in case fatality from MVCs, in spite of the fact that severity in male patients with MVC-related injuries was higher than in females. This is probably due to the fact that females were older than males.

In our study, falls trail MVCs as the second major mechanism of injury, responsible for one-fourth of all injuries, with the highest rates among younger children and older females. This figure is $57 \%$ higher than the global reported figure of $16 \%$. In a previous study, ${ }^{42}$ men and women were at equal risk of fall-related injuries, irrespective of age groups and regions. However, in our study, the percentage of falls in females was double that of males. It has been reported that mortality rates from fall-related injuries were higher among males in the low- and middle-income countries ${ }^{43}$ However, in our study, there was no significant sex difference in mortality rate from these injuries.

Women and young children are at greater risk of domestic burns. ${ }^{42}$ Burn, in our study, was responsible for only $6.8 \%$ of all injuries; yet, it was the cause of $14 \%$ of all deaths, with its highest case fatality rate of $9.7 \%$. Burn-related injuries, in our study, were higher among children aged $0-4$ years, with no sex difference. Several studies have reported higher mortality rates from burn injuries among females than males. ${ }^{449}$ However, no such sex difference was shown in our study. On the other hand, intentional injuries accounted for $5.1 \%$ of all injuries, yet it accounted for only $1.2 \%$ of injuries among females with the highest case fatality rate of $22.2 \%$, reflecting the higher severity of intentional injuries among females, as compared to males $(p=0.004)$.

Globally, most traumatic injuries are minor and the most patients are discharged directly from the emergency department. ${ }^{47-50}$ In the current study, minor injuries constituted onehalf of all injuries, while severe injuries constituted 20.1\%. Injuries in the current study were significantly more severe among males than females, specifically in MVC-related injuries, and this may explain the significantly higher need, by males, for ambulance transportation, disposition from ER to OR as well as ICU admission. Severity was independently associated with higher rates of inhospital mortality which is consistent with findings from other studies..$^{25-28}$

In our study, controlling for age, sex, severity of injury, victims of falls and burns/scalds had higher inhospital mortality rates than victims of MVCs. This finding is inconsistent with results reported from other studies. ${ }^{13}$ This finding is alarming and may highlight potential differences in the care provided to those patients. Our results may be explained by the fact that ISS score does not capture inherent features of fatality induced by different mechanisms of injury in our setting.

Head injuries are one of the most common injuries sustained by patients after MVCs in adults ${ }^{51,52}$ and children. ${ }^{53,54}$ Head injuries in our study accounted for $32.2 \%$ of all injuries. However, they were the cause of death in $70 \%$ of all deaths. This finding was even higher than a figure of $54.4 \%$ in Greece, ${ }^{55}$ which has one of the highest death rates after MVCrelated injuries in the European Union. ${ }^{56}$ Head injuries were significantly higher in males than in females, possibly due to higher rate of MVCs among males. Moreover, in MVCs, women are at a greater risk of injuries to lower extremities due to their smaller stature. ${ }^{57}$ In our study, head, chest and abdomen injuries were significantly higher among males than among females, but injuries of the extremities showed no sex difference. Female sex was an independent predictor of mortality in isolated severe traumatic brain injury ${ }^{58}$ due to differential response of nervous system toward this injury. ${ }^{59}$ However, in our study, case fatality rate in head injuries was not different in males and females, and this finding is in agreement with the findings of others. ${ }^{60}$ Further studies are necessary to delineate sex-related factors that contribute to these disparities. 


\section{Limitations}

Our study has some limitations due to its retrospective design. First, the setting of our study is one of the largest referral trauma centers in the KSA, therefore, the observed trauma severity pattern in our study might not reflect the pattern in the whole kingdom. Second, the standard of care provided in this tertiary center might differ from that in other health care settings in Saudi Arabia. Third, we did not have access to information such as time to arrival which is a possible predictor of inhospital mortality. Therefore, our study might not reflect the full spectrum of the inhospital mortality predictors.

Finally, although mortality is an important indicator of the magnitude of the trauma burden, for each death due to injury, many more survivors are left with permanent disabling sequelae. This is especially important given that about $85 \%$ of our study population were of mild-to-moderate severity with low mortality rates. We did not have access to long-term outcomes to depict the full picture of the trauma burden. Further studies are needed to look into the long-term outcome of trauma patients especially in these groups.

\section{Conclusion}

This study highlights the different patterns of traumatic injuries across age and sex. RTIs are the major contributor to injuries in middle age, while falls dominate the young and old age. Inhospital mortality varies by the pattern of injury with the highest among victims of falls and burns. This suggests the need for a comprehensive national education and prevention programs that address all causes of injuries.

\section{Data sharing statement}

Most of the data supporting our findings is contained within the manuscript, and all others, excluding identifying/confidential respondent data will be shared upon request from the corresponding author.

\section{Acknowledgments}

This study was initiated and supported by King Abdullah International Medical Research Center (KAIMRC), King Saud Bin Abdulaziz University for Health Sciences, MNGHA, KSA. The final draft of the manuscript was English language edited by Macmillan Science Communication. This study was presented in the International Conference in Emergency Medicine and Public Health - Qatar 2016:24 and published as an abstract in the Journal of Emergency Medicine, Trauma \& Acute Care (JEMTAC).
This work was also presented at the 7th Research Summer School program of the King Abdullah International Medical Research Center in August, 2015.

\section{Disclosure}

The authors report no conflicts of interest in this work.

\section{References}

1. Norton R, Kobusingye O. Injuries. NEnglJMed.2013;368(18):1723-1730.

2. Ruikar M. National statistics of road traffic accidents in India. JOTR. 2013;6(1):1.

3. Haagsma JA, Graetz N, Bolliger I, et al. The global burden of injury: incidence, mortality, disability-adjusted life years and time trends from the Global Burden of Disease Study 2013. Inj Prev. 2016;22(1):3-18.

4. Aldana K [webpage on the Internet]. New NHTSA Analysis Shows 2011 Traffic Fatalities Declined by Nearly Two Percent. National Highway Safety Administration. Available from: https://www.nhtsa.gov/roadsafety. Accessed: July 4, 2018.

5. CDC [webpage on the Internet]. Falls Are Leading Cause of Injury and Death in Older Americans. Available from: https://www.cdc.gov/media/ releases/2016/p0922-older-adult-falls.html. Accessed 8 November, 2017.

6. Mansuri F, Al-Zalabani A, Zalat M, Qabshawi R. Road safety and road traffic accidents in Saudi Arabia. A systematic review of existing evidence. Saudi Med J. 2015;36(4):418-424.

7. Memish ZA, Jaber S, Mokdad AH, AlMazroa MA, Murray CJ, Al Rabeeah AA. Peer reviewed: burden of disease, injuries, and risk factors in the kingdom of Saudi Arabia, 1990-2010. Prev Chronic Dis. 2014;11:E169.

8. Saher: an automated traffic control and management system. Ministry of Interior, Kingdom of Saudi Arabia. https://www.moi.gov.sa/wps/portal/ Home/sectors/publicsecurity/traffic/contents/!ut/p/z1/pVNNU8IwE L3zK7hwZHabFpoeI2CDMDIFCzQXp7SpVG34sAPirzfOMI6opDr kkGxm3nvZfbsBUavXazWY60MHX7eTCwgV7_KHuMxXK n6GOUSifY99x-GWQwZ-N2ghCwa9Ub9rE-whzE4ByOg 1 MmZPOXcDMhoQEAY-I0d-x2fccYeIdOi3sM94OPYC20Zm_4 2PZxbDKv4UBIhEletyCVG5jbMsTxr4GRRxrhr4Ei_19gO4TvIUIi8h1GQUnaxt0VSmnvRkJtNW200oWRDy3ZSfrglzzjdVWUk0o-IU9gv3hsB1DoCTO5XpRrpUt3zpVow2-VyD6FabQs9T5N_ uMgr1d0L1M3SIblA2tw-3X79q_LHzUYwPXorVcrXEubm2VsXYRgW1D40g6cxf7u6bfqdBd3fZcWMvQMSpOm7/dz/d5/ L2dBISEvZ0FBIS9nQSEh/. Accessed July 4, 2018.

9. Alghnam S, Alkelya M, Alfraidy M, Al-Bedah K, Albabtain IT, Alshenqeetye O. Outcomes of road traffic injuries before and after the implementation of a camera ticketing system: a retrospective study from a large trauma center in Saudi Arabia. Ann Saudi Med. 2017;37(1):1-9.

10. Al-Shammari N, Bendak S, Al-Gadhi S. In-depth analysis of pedestrian crashes in Riyadh. Traffic Inj Prev. 2009;10(6):552-559.

11. Abbas AK, Hefny AF, Abu-Zidan FM. Seatbelt compliance and mortality in the gulf cooperation council countries in comparison with other high-income countries. Ann Saudi Med. 2011;31(4):347-353.

12. Nagata I, Abe T, Uchida M, Saitoh D, Tamiya N. Ten-year inhospital mortality trends for patients with trauma in Japan: a multicentre observational study. BMJ Open. 2018;8(2):e018635.

13. Haider AH, Chang DC, Haut ER, Cornwell EE, Efron DT. Mechanism of injury predicts patient mortality and impairment after blunt trauma. J Surg Res. 2009;153(1):138-142.

14. Baker SP, O’Neill B, Haddon W Jr, Long WB. The injury severity score: a method for describing patients with multiple injuries and evaluating emergency care. J Trauma. 1974;14(3):187-196.

15. Kim YJ. Injury severity scoring systems: a review of application to practice. Nurs Crit Care. 2012;17(3):138-150.

16. MacKenzie EJ. Injury severity scales: overview and directions for future research. Am J Emerg Med. 1984;2(6):537-549. 
17. Salottolo K, Levy AS, Slone DS, Mains CW, Bar-Or D. The effect of age on Glasgow coma scale score in patients with traumatic brain injury. JAMA Surg. 2014;149(7):727-734.

18. Champion HR, Sacco WJ, Copes WS, Gann DS, Gennarelli TA, Flanagan ME. A revision of the trauma score. J Trauma. 1989;29(5):623-629.

19. Wilson B. Case Studies in Neuropsychological Rehabilitation. New York: Oxford University Press; 1999.

20. Hwabejire JO, Kaafarani HM, Lee J, et al. Patterns of injury, outcomes, and predictors of in-hospital and 1-year mortality in nonagenarian and centenarian trauma patients. JAMA Surg. 2014;149(10):1054-1059.

21. Abbasi H, Bolandparvaz S, Yadollahi M, Anvar M, Farahgol Z. Time distribution of injury-related in-hospital mortality in a trauma referral center in South of Iran (2010-2015). Medicine. 2017;96(21):1-6.

22. Tyson AF, Varela C, Cairns BA, Charles AG. Hospital mortality following trauma: an analysis of a hospital-based injury surveillance registry in sub-Saharan Africa. $J$ Surg Educ. 2015;72(4):e66-e72.

23. Sieling BA, Beem K, Hoffman MT, Yuschak JV, Morris JB. Trauma in nonagenarians and centenarians: review of 137 consecutive patients. Am Surg. 2004;70(9):793-796.

24. Mansuri FA, Al-Zalabani AH, Zalat MM, Qabshawi RI. Road safety and road traffic accidents in Saudi Arabia. A systematic review of existing evidence. Saudi Med J. 2015;36(4):418-424.

25. Dutton RP, Stansbury LG, Leone S, Kramer E, Hess JR, Scalea TM. Trauma mortality in mature trauma systems: are we doing better? An analysis of trauma mortality patterns, 1997-2008. J Trauma. 2010;69(3):620-626.

26. Papa L, Langland-Orban B, Kallenborn C, et al. Assessing effectiveness of a mature trauma system: association of trauma center presence with lower injury mortality rate. J Trauma. 2006;61(2):261-267.

27. Moore L, Hanley JA, Turgeon AF, Lavoie A. Evaluation of the long-term trend in mortality from injury in a mature inclusive trauma system. World J Surg. 2010;34(9):2069-2075.

28. Lansink KW, Leenen LP. Do designated trauma systems improve outcome? Curr Opin Crit Care. 2007;13(6):686-690.

29. Nizamo H, Meyrowitsch DW, Zacarias E, Konradsen F. Mortality due to injuries in Maputo city, Mozambique. Int J Inj Contr Saf Promot. 2006;13(1):1-6.

30. Jacobs DG, Plaisier BR, Barie PS, et al; EAST Practice Management Guidelines Work Group. Practice management guidelines for geriatric trauma: the EAST Practice Management Guidelines Work Group. J Trauma. 2003;54(2):391-416.

31. Calland JF, Ingraham AM, Martin N, et al; Eastern Association for the Surgery of Trauma. Evaluation and management of geriatric trauma: an Eastern association for the surgery of trauma practice management guideline. J Trauma. 2012;73(5):S345-S350.

32. Ansari S, Akhdar F, Mandoorah M, Moutaery K. Causes and effects of road traffic accidents in Saudi Arabia. Public Health. 2000;114:37-39.

33. Barrimah I, Midhet F, Sharaf F. Epidemiology of road traffic injuries in Qassim region, Saudi Arabia: consistency of police and health data. Int J Health Sci (Qassim). 2012;6:31-41.

34. Trajano AD, Pereira BM, Fraga GP. Epidemiology of in-hospital trauma deaths in a Brazilian university hospital. BMC Emerg Med. 2014;14(1):22.

35. Northern Ireland Statistics and Research Agency (NISRA). 2009 MidYear Population Estimates. 2010. Available from: https://www.nisra. gov.uk/statistics/population/mid-year-population-estimates. Accessed July 4, 2018.

36. Office for National Statistics (ONS). Mortality Statistics Deaths Registered in 2009 Tables 1 and 5.19. 2010. Available from: http://webarchive. nationalarchives.gov.uk/20160108063955/http://www.ons.gov.uk/ons/ rel/vsob1/mortality-statistics--deaths-registered-in-england-and-wales-series-dr-/2009/index.html. Accessed July 4, 2018.

37. Mock C, Quansah R, Krishnan R, Arreola-Risa C, Rivara F. Strengthening the prevention and care of injuries worldwide. Lancet. 2004;363(9427):2172-2179.
38. Kobusingye OC, Guwatudde D, Owor G, Lett RR. Citywide trauma experience in Kampala, Uganda: a call for intervention. Inj Prev. 2002;8(2):133-136.

39. Nizamo H, Meyrowitsch DW, Zacarias E, Konradsen F. Mortality due to injuries in Maputo city, Mozambique. Int J Inj Contr Saf Promot. 2006;13(1):1-6.

40. World Health Organization [webpage on the Internet]. Gender and Road Traffic Injuries. 2002. Available from: http://www.who.int/gender/ other_health/en/gendertraffic.pdf. Accessed March 24, 2017.

41. El-Menyar A, El-Hennawy H, Al-Thani $\mathrm{H}$, et al. Traumatic injury among females: does gender matter? J Trauma Manag Outcomes. 2014;8(1):8.

42. World Health Organization. D.o.I.a.V.P: Noncommunicable Disease and Mental Health Cluster, The Injury Chart Book. Fall-Related Injuries. Geneva, Switzerland: World Health Organization; 2002.

43. Attia AF, Sherif AA, Mandil AM, Massoud MN, Abou-Nazel MW, Arafa MA. Epidemiological and sociocultural study of burn patients in Alexandria, Egypt. East Mediterr Health J. 1997;3(3):452-461.

44. Groohi B, Alaghehbandan R, Lari AR. Analysis of 1089 burn patients in province of Kurdistan, Iran. Burns. 2002;28(6):569-574.

45. Estahbanati HK, Kashani PP, Ghanaatpisheh F. Frequency of Pseudomonas aeruginosa serotypes in burn wound infections and their resistance to antibiotics. Burns. 2002;28(4):340-348.

46. Kobusingye OC, Guwatudde D, Owor G, Lett RR. Citywide trauma experience in Kampala, Uganda: a call for intervention. Inj Prev. 2002;8(2):133-136.

47. Tyson AF, Varela C, Cairns BA, Charles AG. Hospital mortality following trauma: an analysis of a hospital-based injury surveillance registry in sub-Saharan Africa. $J$ Surg Educ. 2015;72(4):e66-e72.

48. Kobusingye $\mathrm{O}$, Guwatudde $\mathrm{D}$, Lett R. Injury patterns in rural and urban Uganda. Inj Prev. 2001;7(1):46-50.

49. Kobusingye OC, Lett RR. Hospital-based trauma registries in Uganda. J Trauma. 2000;48(3):498-502.

50. Gennarelli TA, Champion HR, Sacco WJ, Copes WS, Alves WM. Mortality of patients with head injury and extracranial injury treated in trauma centers. J Trauma. 1989;29:1193-1202.

51. Swierzewski MJ, Feliciano DV, Lillis RP, Illig KA, States JD. Deaths from motor vehicle crashes: patterns of injury in restrained and unrestrained victims. J Trauma. 1994;37:404-407.

52. Scheidler MG, Shultz BL, Schall L, Ford HR. Risk factors and predictors of mortality in children after ejection from motor vehicle crashes. J Trauma. 2000;49(5):864-868.

53. Tepas JJ 3rd, DiScala C, Ramenofsky ML, Barlow B. Mortality and head injury: the pediatric perspective. J Pediatr Surg. 1990;25:92-96.

54. Markogiannakis H, Sanidas E, Messaris E, et al. Predictors of in-hospital mortality of trauma patients injured in vehicle accidents. Ulus Travma Acil Cerrahi Derg. 2008;14(2):125-131.

55. Markogiannakis H, Sanidas E, Messaris E, Koutentakis D, Alpantaki $\mathrm{K}$, Kafetzakis A, Tsiftsis D. Motor vehicle trauma: analysis of injury profiles by road-user category. Emerg Med J. 2006;23(1):27-31.

56. World Health Organization [webpage on the Internet]. Gender and Road Traffic Injuries. 2002. Available from: http://www.who.int/gender/ other_health/en/gendertraffic.pdf. Accessed November 4, 2017.

57. Kraus JF, Peek-Asa C, McArthur D. The independent effect of gender on outcomes following traumatic brain injury: a preliminary investigation. Neurosurg Focus. 2000;8(1):e5.

58. Ottochian M, Salim A, Berry C, Chan LS, Wilson MT, Margulies DR. Severe traumatic brain injury: is there a gender difference in mortality? Am J Surg. 2009;197:155-158.

59. Farace E, Alves WM. Do women fare worse? A metaanalysis of gender differences in outcome after traumatic brain injury. Neurosurg Focus. 2000;8(1):e6.

60. Demetriades D, Murray J, Charalambides K, et al. Trauma fatalities: time and location of hospital deaths. J Am Coll Surg. 2004;198(1): $20-26$. 
The Open Access Emergency Medicine is an international, peerreviewed, open access journal publishing original research, reports, editorials, reviews and commentaries on all aspects of emergency medicine. The manuscript management system is completely online and includes a very quick and fair peer-review system, which is all

\section{Dovepress}

easy to use. Visit http://www.dovepress.com/testimonials.php to read real quotes from published authors.

Submit your manuscript here: https://www.dovepress.com/open-access-emergency-medicine-journal 